\title{
Pemetaan Pemukiman dan Potensi Wilayah Desa Berbasis WebGIS
}

\author{
Dedy Mirwansyah $^{1 *}$, Riyayatsyah ${ }^{2}$, Deny Martadinata ${ }^{3}$ \\ 1,2. Program Studi Manajemen Informatika, Fakultas Ilmu Komputer, Universitas Mulia \\ ${ }^{3}$ Program Studi Sistem Informasi, Fakultas Ilmu Komputer, Universitas Mulia \\ *dedy.m@universitasmulia.ac.id
}

\begin{abstract}
The need for information is increasingly high and information is one of the most important parts in the development of human life technology. In this study, the objects that are used as this type of information are information on settlements and the potential of the Benua Puhun village, Muara Kaman District. From the results of problem identification, there are two points, namely the village government does not have digital documented settlement map information and the village government does not have information on the potential map of the area. So this research aims to build a geographic information system, namely mapped settlements and territorial boundaries to make it easier for each RT to accommodate its citizens, and to find out or describe the potential of the village area such as social and cultural, income, economic products, environmental security from a disaster and non-disaster perspective. so that the village government has WebGis-based digital data. The system development method used in this research is the RAD (Rapid Application Development) method which consists of 3 stages, namely planning the requirements, the RAD design workshop, and implementation. This system makes use of the leaflet feature which is connected to OpenStreetMap and is built using the laravel framework. The conclusions that can be drawn from this research include the use of geographic information systems (GIS), especially web-based ones, which are useful for village governments as technology utilization in digitizing websitebased data. Utilization of GIS also provides useful information for the public regarding potential settlements and rural areas.
\end{abstract}

Keywords: geographical information systems, WebGis, RAD, settlements, regional potential

\begin{abstract}
Abstrak
Kebutuhan akan informasi semakin hari semakin tinggi dan informasi adalah salah satu bagian terpenting dalam perkembangan teknologi kehidupan manusia. Dalam penelitian ini, objek yang dijadikan jenis informasi tersebut adalah informasi pemukiman dan potensi wilayah desa Benua Puhun Kecamatan Muara Kaman. Dari hasil identifikasi masalah terdapat dua point yaitu pemerintah desa belum memiliki informasi peta pemukiman yang terdokumentasi digital dan pemerintah desa belum memiliki informasi peta potensi wilayah. Sehinggan penelitian ini bertujuan untuk membangun sistem informasi geografis yaitu terpetakan pemukiman dan batas wilayah guna mempermudah setiap RT dalam mengakomodir warganya, dan untuk mengetahui atau menggambarkan potensi wilayah desa seperti sosial dan budaya, pendapatan, produk ekonomi, keamanan lingkungan dari segi bencana dan non bencana, sehingga pemerintah desa memiliki data digital berbasis WebGis. Metode pengembangan sistem yang digunakan dalam penelitian ini yaitu metode RAD (Rapid Application Development) yang terdiri dari 3 tahapan yaitu perencanaan syarat-syarat, workshop desain RAD, dan implementasi. Sistem ini memamfaatkan fitur leaflet yang terkoneksi dengan OpenStreetMap dan dibangun menggunakan framework laravel. Kesimpulan yang yang dapat ditarik dari penelitian ini antara lain adalah pemanfaatan dari sistem informasi geografis (SIG) khususnya yang berbasis web berguna untuk pemerintah desa sebagai pemamfaatan teknologi dalam digitalisasi data berbasis website. Pemanfaatan SIG ini juga memberikan informasi yang berguna bagi masyarakat mengenai lokasi pemukiman dan potensi wilayah desa.
\end{abstract}

Kata kunci: sistem informasi geografis, WebGis, RAD, pemukiman, potensi wilayah

\section{Pendahuluan}

\subsection{Latar Belakang}

Seiring dengan jumlah penduduk yang semakin bertambah dari waktu ke waktu dan terjadinya proses urbanisasi dan transmigrasi yang sangat cepat dalam kehidupan masyarakat menyebabkan kebutuhan akan tempat tinggal juga meningkat secara proporsional. Upaya masyarakat untuk memperbaiki tingkat pendapatan, pendidikan, 
kesejahteraan, lingkungan aman dan kehidupan yang lebih layak adalah dengan memfaatkan dan mengembangkan potensi wilayahnya. Ini akan menjadi tatangan tersendiri bagi perangkat desa dalam mengakomidir warga agar tercapai pemukiman yang tertata dan terdata secara terus menerus serta potensi wilayah yang terus berkembang. Untuk menjawab tantangan tersebut, salah satunya cara yang dapat dilakukan adalah memanfaatkan Sistem Informasi Geografis (SIG). SIG merupakan sistem komputer yang dirancang untuk mendapatkan, menyimpan, memanipulasi, menganalisis, dan mengelola data geografis kemudian disajikan menjadi sebuah informasi [1]. Dalam perkembangannya SIG dapat digunakan untuk mempermudah dalam menentukan kebijakan yang akan diambil [2]. Adapun rumusan masalah dalam penelitian ini adalah :

1. Pemerintah Desa belum memiliki informasi peta pemukiman yang terdokumentasi digital.

2. Pemerintah Desa belum memiliki informasi peta potensi wilayah.

Teknologi WebGIS telah

dikembangkan oleh instansi pemerintahan, perusahaan, lembaga penelitian, dan masyarakat umum untuk digunakan sebagai pendukung keputusan, akses data spasial, eksplorasi dan visualisasi data spasial, ruang pengolahan analisis data dan pemodelan serta digunakan untuk mengintegrasikan layanan berbasis geo spasial dengan layanan proses komputasi dan lingkungan dalam bentuk website.[3]

Melengkapi teknologi SIG digunakan layanan OpenStreetMap. Open Street Map API adalah suatu layanan WEB (Web Map Service) yang menyediakan akses langsung ke server basis data geospasial openstreetmap, tujuannya adalah hanya untuk mengakses basis data secara langsung. Hampir semua map editor untuk OpenStreetMap (OSM) menggunakan API ini. Karena server dari API didanai hanya melalui donasi maka penggunaan API untuk tujuan yang tidak jelas, seperti mengambil data dalam jumlah besar maka osm akan memblok akses ke servernya tanpa suatu peringatan [4]. Sesuai dengan tujuan, SIG ini berfokus pada pemukiman dan potensi wilayah desa. Permukiman menurut [5] dapat diartikan sebagai bentukan baik buatan manusia ataupun alami dengan segala kelengkapannya yang digunakan manusia sebagai individu maupun kelompok untuk bertempat tinggal baik sementara maupun menetap dalam rangka menyelenggarakan kehidupannya. Sedangkan potensi ialah segala sesuatu hal yang dapat dijadikan sebagai bahan atau sumber yang akan dikelola baik melalui usaha yang dilakukan manusia maupun yang dilakukan melalui tenaga mesin dimana dalam pengerjaannya potensi dapat juga diartikan sebagai sumber daya yang ada disekitar kita. [6]

Dalam penelitian ini, metode pengembangan sistem yang digunakan adalah model Rapid Application Development. Menurut [7], "RAD adalah suatu pendekatan berorientasi objek terhadap pengembangan sistem yang mencakup suatu metode pengembangan serta perangkat-perangkat lunak. RAD bertujuan mempersingkat waktu yang biasanya diperlukan dalam siklus hidup pengembangan sistem tradisional antara perancangan dan penerapan suatu sistem informasi. Pada akhirnya, RAD sama-sama berusaha memenuhi syarat-syarat bisnis yang berubah secara cepat."

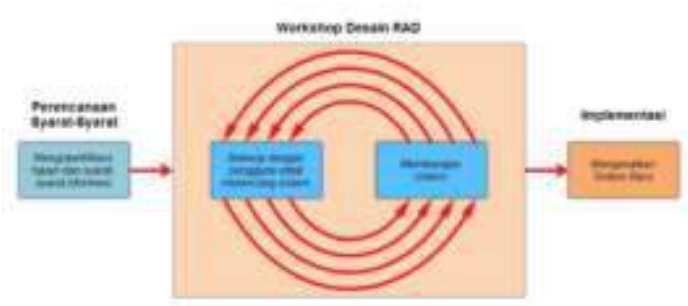

Gambar 1. Proses RAD (Rapid Application Development)

\section{Metoda Penelitian}

\subsection{Tahapan Penelitian}

Adapun tahapan penelitian yang dilakukan dalam penelitian ini adalah menggunakan metode RAD (Rapid Application Development) sebagai berikut: Metode pengembangan sistem yang digunakan dalam penelitian ini yaitu metode RAD (Rapid Application Development). Metode ini dipilih karena waktu yang diperlukan relative lebih singkat karena 
pengguna dapat melihat dan mengomentari di tahap desain yaitu sebelum masuk ke tahap implementasi (pembuatan aplikasi).

1) Perencanaan Syarat-syarat

Dengan melakukan metode pengamatan secara langsung dapat mengetahui bagaimana peneliti dapat menentukan pokok permasalahan yang ada seperti kesalahankesalahan dalam sistem lama yang masih menggunakan sistem manual. Dari analis sistem tersebut dapat ditetapkan tujuan perancangan dan pengajuan usulan. Tahapan yang dilakukan antara lain adalah:

a. Studi Literatur

b. Pengumpulan Data

c. Mengidentifikasi masalah.

2) Workshop Desain RAD

Setelah mengetahui kebutuhan yang akan digunakan, maka analis mendesain sistem yang diusulkan agar dapat berjalan dengan lebih baik. Penerapan dalam desain sistem menggunakan flowchart yang dibuat meliputi sebagai berikut:

a. Pembentukan SIG

b. Desain Layout Web

3) Implementasi

Setelah melakukan analisis sistem dan perancangan sistem secara rinci, maka saatnya sistem untuk diimplementasikan. Pada tahap ini terdapat dua aktifitas yang akan dilakukan oleh programmer yaitu :

a. Pemrograman

Dalam tahap ini, hasil desain dimasukkan ke dalam bentuk bahasa pemrograman yangdigunakan agar dibangun aplikasi.

Berikut ini merupakan alur dalam pembuatan sistem informasi geografis menggunakan fasilitas leaflet yang terintegrasi dengan Open Street Map yang digunakan dalam SIG pemukiman dan potensi wilayah. Secara umum langkahnya terdiri dari pengumpulan data spasial dan data atribut, download dan melengkapi data dengan editor OpenStreetMap, kemudian membangun aplikasi berbasis webgis menggunakan Laragon dan fitur phpMyAdmin untuk penyusunan basis data. Visual Studio untuk menyusun bahasa pemrograman dengan pemanggilan OpenStreetMap API untuk peta. Pengumpulan data dilakukan dengan melakukan survei koordinat pemukiman dan potensi-potensi wilayah sesuai batasan penilitian se-Desa Benua Puhun menggunakan GPS, sedangkan data atribut diperoleh dari ketua RT dan Kantor Desa Benua Puhun. Pada tahapan ini juga dilakukan download data dari web OpenStreetMap dan kemudian melengkapi fiturnya dengan dijitasi sesuai dengan topologinya mengacu pada citra Bing Map yang ditampilkan. Hasil editing kemudian diupload ke OpenStreetMap. Tahap selanjutnya yaitu pembuatan aplikasi SIG yang diawali dengan pembuatan basis data menggunakan phpMyAdmin. Menambahkan fitur peta memanfaatkan OpenStreetMap API. Peta dilengkapi dengan marker persebaran bangunan pemukiman dan marker potensi wilayah.

\section{b. Pengujian}

Setelah tahap pembuatan aplikasi, maka tahap selanjutnya adalah menguji sistemnya agar dapat digunakan tanpa menemukan kendala-kendala apapun. Adapun metode uji coba yang dilakukan menggunakan metode black box testing.

\subsection{Model dan Rancangan Penelitian}

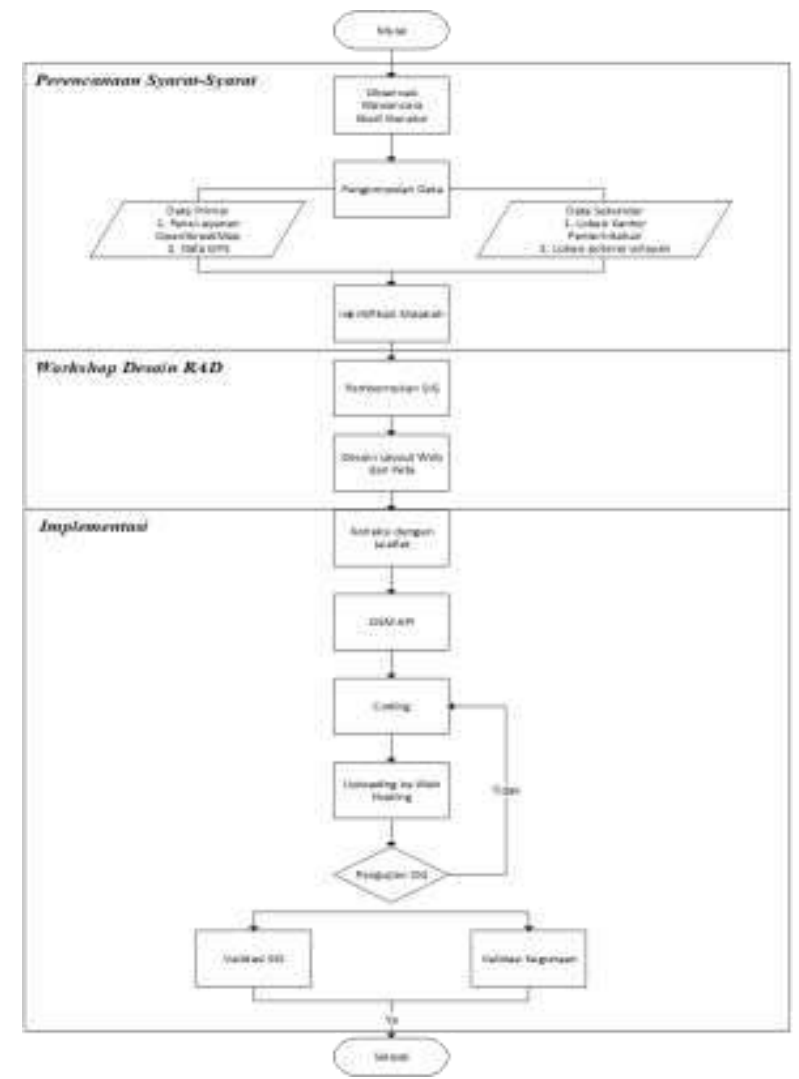

Gambar 2. Model dan Rancangan Penelitian 


\subsection{Teknik Pengumpulan Data}

Pada penelitian ini

penulis

menggunakan beberapa metode dalam pengumpulan data, yaitu sebagai berikut :

\section{Metode Observasi}

Pengamatan dilakukan secara langsung agar dapat memastikan kebutuhan dari user dalam hal ini perangkat desa yaitu staf desa dan ketua RT, tahapan ini juga memerlukan dokumentasi.

2. Metode Wawancara

Setelah melakukan pengamatan, selanjutnya melakukan tanya jawab dengan staf desa dan ketua RT untuk memproleh data tambahan dari metode pengamatan.

3. Metode Studi Literatur

Selanjutnya yaitu melakukan studi literatur, dengan cara mempelajari teori-teori dari buku dan browsing melalui internet agar dapat membantu serta mendukung dalam penelitian ini.

\subsection{Analisa Data}

Analisis data yang dilakukan melalui beberapa tahapan berikut:

1. Mengidentifikasi permasalahan yang didapat dari pengumpulan data primer dan data sekunder.

2. Setelah hasil identifikasi didapat maka dirancang untuk pembuatan sistem informasi geografis.

3. Seetelah sistem terbagun maka dilakukan pengujian dengan metode black box testing.

4. Menarik keputusan dan kesimpulan.

\section{Hasil Penelitian}

\subsection{Perencanaan syarat-syarat}

a Pengumpulan Data

Pengumpulan data dilakukan untuk mengetahui sejauh mana potensi yang dimiliki desa yang diteliti, terutama untuk sebagai bahan identifikasi masalah dan analisis kebutuhan system yang akan di bangun pada desa. Sumber data terbagi menjadi dua yaitu data primer yang meliputi data layanan openstreetmap dan data koordinat, data berikutnya adalah data sekunder yang meliputi lokasi atau alamat kantor-kantor pemerintahan dan lokasi wilayah desa yang memiliki potensi untuk dikembangkan.

\section{b Data Primer}

Data primer diperoleh dari layanan OpenStreetMap yang telah terdigitasi dalam bentuk polygon dan point oleh relawanrelawan OpenStreetMap lalu dikoneksikan melalui leaflet ke sistem informasi geografis desa yang telah dibangun. Data primer selanjutnya adalah data koordinat setiap fasilitas-fasilitas penting di desa. Berikut data koordinat desa:

Tabel 1. Data Koordinat Desa

\begin{tabular}{|c|c|c|c|}
\hline NO & $\mathbf{X}$ & $\mathbf{Y}$ & KETERANGAN \\
\hline 1 & 116.7954558 & -0.2758457 & LKP PanduEtam Family \\
\hline 2 & 116.8022079 & -0.2401123 & Masjid Al-Hidayah \\
\hline 3 & 116.8084193 & -0.2433058 & PDAM Tirtajaya \\
\hline 4 & 116.7926673 & -0.2695037 & $\begin{array}{ll}\text { SMAN } & 2 \\
\text { KAMAN } & \text { MUARA }\end{array}$ \\
\hline 5 & 116.7936473 & -0.2689575 & $\begin{array}{l}\text { Lapangan Sepak Bola } \\
\text { Gelora Haur Kuning }\end{array}$ \\
\hline 6 & 116.8081708 & -0.2591122 & TPA Desa Benua Puhun \\
\hline 7 & 116.8070161 & -0.287887 & TPU Tanjung Rempong \\
\hline 8 & 116.7882279 & -0.2716789 & TPU Tanjung Kriu \\
\hline 9 & 116.8001178 & -0.2806337 & Langgar Al-Mukaramah \\
\hline 10 & 116.7994104 & -0.2801908 & $\begin{array}{lr}\text { Lapangan } & \text { Sepak Bola } \\
\text { Tanjung } & \text { Rempong } \\
\text { RT.007 } & \end{array}$ \\
\hline 11 & 116.7996924 & -0.2797074 & TK Melati Harapan \\
\hline 12 & 116.7988257 & -0.2792923 & SDN 019 Muara Kaman \\
\hline 13 & 116.798196 & -0.2792128 & Pasar Desa Benua Puhun \\
\hline 14 & 116.7976173 & -0.2781383 & SDN 01 Muara Kaman \\
\hline 15 & 116.7981213 & -0.2782171 & $\begin{array}{l}\text { Gedung Serbaguna Desa } \\
\text { Benua Puhun }\end{array}$ \\
\hline 16 & 116.7974148 & -0.2783099 & Area Terbuka Desa \\
\hline 17 & 116.7974641 & -0.2778332 & TK Al-Mukmin \\
\hline 18 & 1167974487 & -0.2776508 & $\begin{array}{l}\text { Kantor PKK Desa Benua } \\
\text { Puhun }\end{array}$ \\
\hline 19 & 116.7973692 & -0.2777577 & $\begin{array}{l}\text { Kantor } \\
\text { Puhun }\end{array}$ BPD $\quad$ Benua \\
\hline 20 & 116.797676 & -0.2773286 & Gudang Desa \\
\hline 21 & 116.7972197 & -0.2776977 & $\begin{array}{l}\text { Kantor Desa } \\
\text { Puhun }\end{array}$ \\
\hline 22 & 116.7978879 & -0.278443 & $\begin{array}{l}\text { Posyandu Desa Benua } \\
\text { Puhun }\end{array}$ \\
\hline 23 & 116.7971496 & -0.2776189 & Posbindu \\
\hline 24 & 116.7980136 & -0.278544 & $\begin{array}{l}\text { Kantor Koperasi Tanah } \\
\text { Sama }\end{array}$ \\
\hline 25 & 116.7945871 & -0.260107 & SMPN 03 Muara Kaman \\
\hline 26 & 116.7960399 & -0.2768257 & Masjid Al-Mukmin \\
\hline 27 & 116.8042568 & -0.2412177 & RT. 001 \\
\hline 28 & 116.7941858 & -0.2745908 & RT. 002 \\
\hline 29 & 116.7956674 & -0.2753478 & RT. 003 \\
\hline 30 & 116.7960838 & -0.2761474 & RT. 004 \\
\hline 31 & 116.7969941 & -0.2782459 & RT. 005 \\
\hline 32 & 116.7977142 & -0.2789671 & RT. 006 \\
\hline 33 & 116.7991516 & -0.2805445 & RT. 007 \\
\hline 34 & 116.8005406 & -0.281839 & RT. 008 \\
\hline 35 & 116.8016172 & -0.2827563 & RT. 009 \\
\hline 36 & 116.8022586 & -0.2832337 & RT. 010 \\
\hline
\end{tabular}

Tabel 2. Data Potensi Wilayah Desa

NAMA POTENSI

Area Kantor Pemerintah Kantor pemerintahan terpusat Desa satu area, memudahkan masyarakat untuk melakukan pelayanan

Lapangan Bola Haur Lapangan olahraga utama Kuning desa,selain tempat olahraga juga lokasi masyarakat untuk berjualan yang telah disediakan pemerintah desa stand-stand pedagang.

\begin{tabular}{|ll|}
\hline Gedung Serba Guna & $\begin{array}{l}\text { Kegiatan masyarakat terpusat } \\
\text { di gedung serba guna }\end{array}$ \\
\hline $\begin{array}{l}\text { RT 003 Usahan Rumahan } \\
\text { Pengolahan Ikan }\end{array}$ & $\begin{array}{l}\text { Beberapa warga sebagai } \\
\text { pengolah ikan salai dan ikan }\end{array}$ \\
\hline
\end{tabular}




\begin{tabular}{|c|c|}
\hline \multicolumn{2}{|c|}{ METIK VOLUME. 4 NOMOR. 22020} \\
\hline NAMA & POTENSI \\
\hline & $\begin{array}{l}\text { asin yang dipasarkan di desa } \\
\text { dan desa-desa terdekat }\end{array}$ \\
\hline $\begin{array}{l}500 \text { Ha Optimalisasi Lahan } \\
\text { Rawa (Percetakan sawah) }\end{array}$ & $\begin{array}{l}\text { Lahan dibagikan kepada } \\
\text { masyarakat untuk dikelola } \\
\text { bersama (Lumbung pangan) }\end{array}$ \\
\hline \multicolumn{2}{|c|}{$\begin{array}{lll}\text { Kantor PKK Pengolahan } & \text { Warga mengolah ikan menjadi } \\
\text { kerupuk ikan } & \text { kerupuk di akomodir oleh } \\
& \text { PKK Desa }\end{array}$} \\
\hline \multicolumn{2}{|r|}{ POTENSI } \\
\hline Palabuhan Desa & $\begin{array}{l}\text { Perdagangan barang jalur } \\
\text { sungai dan menarik } \\
\text { wisatawan }\end{array}$ \\
\hline $\begin{array}{l}\text { Benua } \\
\text { Seberang }\end{array}$ & $\begin{array}{l}\text { Pengolahan limbah sawit oleh } \\
\text { BUMDES }\end{array}$ \\
\hline $\begin{array}{l}\text { Perusahaan Batu } \\
\text { Bara }\end{array}$ & $\begin{array}{l}\text { Terdapat } 2 \text { perusahaan besar } \\
\text { batu bara di area desa, PT. } \\
\text { Koetaindo dan PT. Bayan }\end{array}$ \\
\hline Pabrik Sawit & $\begin{array}{l}\text { Pabrik pengolahan dan } \\
\text { perkebunan sawit (PT. PMM) }\end{array}$ \\
\hline $\begin{array}{l}\text { Tangki Minyak } \\
\text { Sawit }\end{array}$ & $\begin{array}{l}\text { Pabrik penampungan minyak } \\
\text { sawit (PT.KED) }\end{array}$ \\
\hline Pelabuhan puntun & $\begin{array}{l}2 \text { Lokasi } \\
\text { pelabuhan } \\
\text { perusahaan batu bara dan } \\
\text { sawit (PT. CAP dan PT. } \\
\text { DSN) }\end{array}$ \\
\hline $\begin{array}{l}2 \text { Ha } r \text { area } \\
\text { perkebunan } \\
\text { desayur }\end{array}$ & $\begin{array}{l}\text { Masyarakat mengelola lahan } \\
\text { untuk menanam sayur yang di } \\
\text { akomodir dasa wisma }\end{array}$ \\
\hline
\end{tabular}

c Identifikasi Masalah

Dari hasil observasi dan studi literatur pada lokasi penelitian terdapat beberapa permasalah yaitu pemerintah desa belum memiliki peta pemukiman dan potensi wilayah yang terdokumentasi secara digital untuk mempermudah pengeolaan data warga oleh ketua RT dan staf desa. Dalam merumuskan solusi bagi permasalahan ini, peneliti tertarik membangun sebuah peta yang mengakomidir pemukiman dan potensi wilayah berbasis webgis yang dikelola oleh RT dan staf desa.

d Analisa Kebutuhan Sistem

Dengan memahami permasalahan identifikasi masalah, maka kebutuhan sistem yang diperlukan yaitu sistem informasi geografis desa sehingga pemerintah desa Benua Puhun memiliki dokumentasi data digital pemukiman dan potensi wilayah berbasis WebGis.Sistem yang akan dibagun nantinya tidak sepenuhnya dikelola oleh desa mitra terutama dalam penambahan data pemukiman dan arsir potensi wilayah pada peta karena data geografis masih memamfaatkan fasilitas leaflet yang terkoneksi dengan layanan openstreetmap dan diperbaharui oleh kontributor-kontirbutor OpenStreetMap.

\subsection{Workshop desain RAD}

Pembentukan Sistem Informasi

Geografis. Sistem informasi geografis menggunakan fasilitas leaflet yang terintegrasi dengan OpenStreetMap yang digunakan dalam SIG pemukiman dan potensi wilayah. Secara umum langkahnya terdiri dari pengumpulan data spasial dan data atribut, download dan melengkapi data dengan editor OpenStreetMap, kemudian membangun aplikasi berbasis webgis menggunakan Laragon dan fitur phpMyAdmin untuk penyusunan basis data. Visual Studio untuk menyusun bahasa pemrograman dengan pemanggilan OpenStreetMap API untuk peta. Pengumpulan data dilakukan dengan melakukan survei koordinat pemukiman dan potensi-potensi wilayah sesuai batasan penilitian se-Desa Benua Puhun menggunakan GPS, sedangkan data atribut diperoleh dari ketua RT dan Kantor Desa Benua Puhun.

Pada tahapan ini juga dilakukan download data dari web OpenStreetMap dan kemudian melengkapi fiturnya dengan dijitasi sesuai dengan topologinya mengacu pada citra Bing Map yang ditampilkan. Hasil editing kemudian di-upload ke OpenStreetMap. Tahap selanjutnya yaitu pembuatan aplikasi SIG yang diawali dengan pembuatan basis data menggunakan phpMyAdmin. Menambahkan fitur peta memanfaatkan OpenStreetMap API. Peta dilengkapi dengan marker persebaran bangunan pemukiman dan marker potensi wilayah.

\subsection{Implementasi}

Setelah desain sistem selesai, maka tahap berikutnya adalah mengimplementasikan hasil rancangan tersebut. Setelah melakukan proses pemograman, maka hasil dari sistem informasi geografis yang telah dibangun sebagai berikut: 


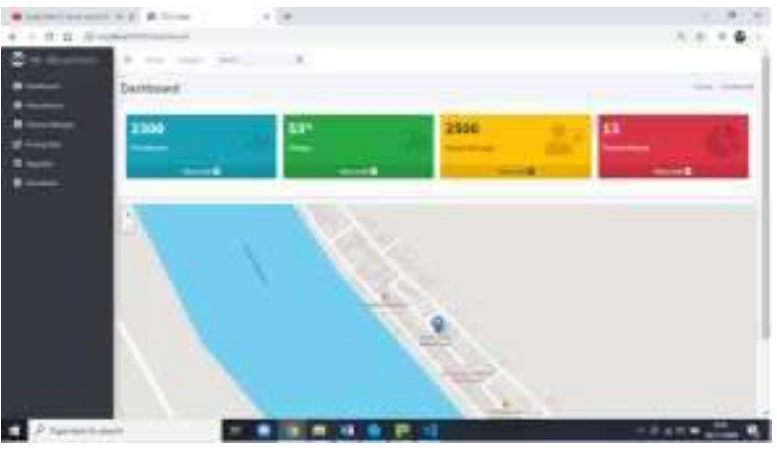

Gambar 3. Dashboard

Halaman dashboard memuat beberapa informasi seperti jumlah pemukiman desa, status pekerjaan masyarakat, jumlah kepala keluarga dan daftar potensi wilayah desa serta tampil peta digital yang di koneksi dengan layanan OpenStreetMap. Informasi pada halaman dashboard akan terus berubah seiring dating yang dikelola oleh RT dan staf Desa sehingga masyarakat desa dan investor luar dapat memantau potensi-potensi desa dengan mudah.

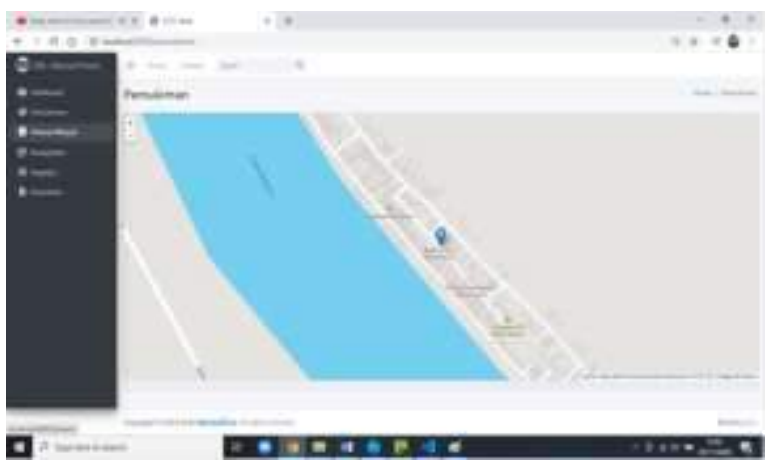

Gambar 4.Pemukiman

Pada halaman pemukiman ditampilkan peta digital sebaran pemukiman yang terkoneksi dengan layanan OpenStreetMap, sebaran pemukiman tersebut merupakan digitasi dari kontirbutor OpenStreetMap.

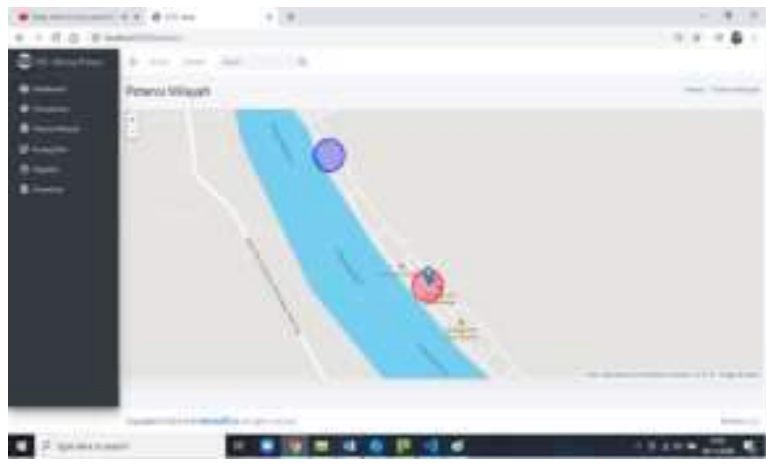

Gambar 5. Potensi Wilayah
Pada halaman potensi wilayah akan ditampilkan atau di arsir wilayah desa yang memiliki potensi terutama potensi dari segi ekonomi dan layanan masyarakat.

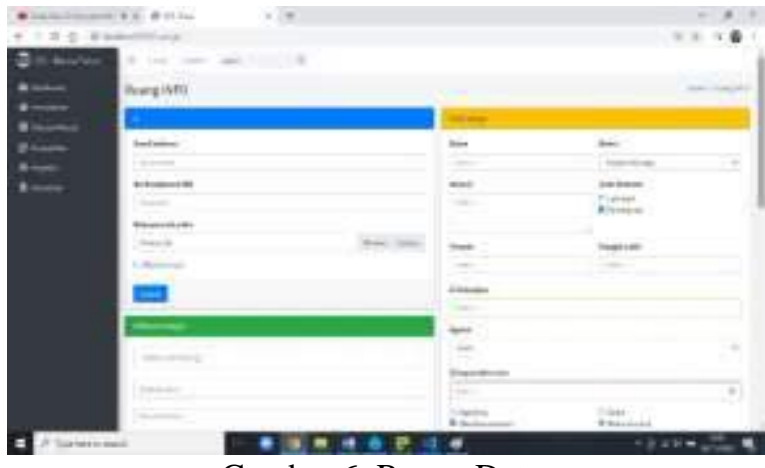

Gambar 6. Ruang Data

Pada halaman ruang data akan dibagi beberapa halaman untuk RT dan untuk staf desa, ruang data akan menjadi halaman terpusat dalam input data bagi sistem informasi geografis desa.

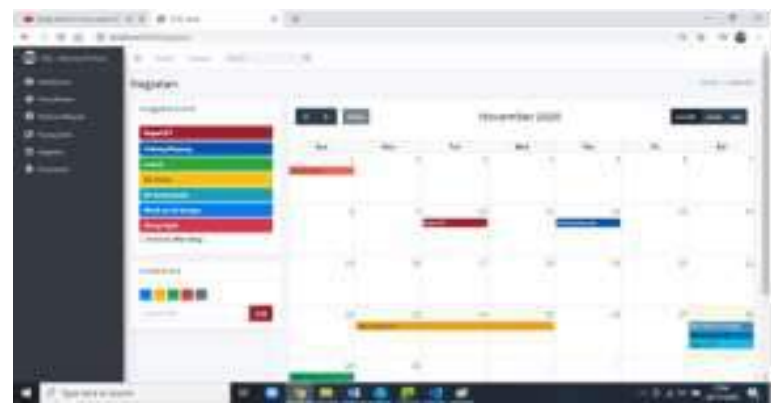

Gambar 7. Kegiatan

Pada halaman kegiatan akan memuat informasi kegiatan RT dan kegiatan desa yang di perbaharui terus menerus oleh RT dan staf desa agar memudahkan warga dalam informasi kegiatan RT dan Desa.

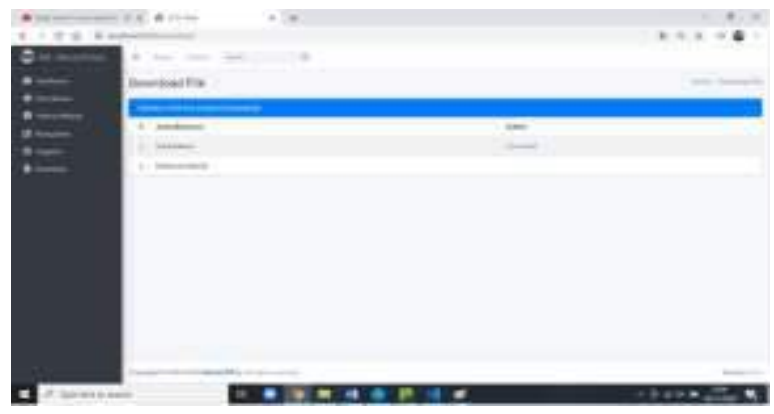

Gambar 8. Download

Pada halaman download berisi dokumen-dokumen surat edaran dan perda perihal desa. 
Hasil penelitian pada desa Benua Puhun berupa produk yaitu sistem informasi geografis desa, pembangunan sistem ini telah sesuai dengan kebutuhan desa berdasarakan hasil analisis kebutuhan dan observasi wilayah pada desa Benua Puhun. Pada pembangunan sistem informasi geografis desa masih masih kekurangan fitur-fitur pendukung dan akan terus dikembangkan oleh desa dan mitra.Hasil penelitian ini akan diserahakan pada desa yang diteliti dan akan dilakukan proses valisasi sistem dan validasi kegunaan saat tim melalukan pengabdian masyarakat berupa bimbingan teknis penggunaan SIG pada ketua RT dan staf desa tahun 2021.

\section{Kesimpulan}

Dari identifikasi masalah dan target luaran serta hasil implementasi dapat disimpulkan:

1. Sistem informasi geografis desa telah terbangun sesuai target luaran pada penelitina ini yaitu peta digital desa dan data potensi wilayah desa dalam bentuk webgis.

2. Proses informasi pada masyarakat, pemerintah dan stakeholder akan menjadi lebih mudah dan terpusat melalui sistem informasi geografis desa.

\section{Saran}

Setelah sistem informasi geografis desa terealisasi dengan baik, maka saran untuk mengembangkan SIG desa lebih lanjut adalah sebagai berikut:

1. Menambah fitur-fitur pada SIG desa seperti informasi keamanan lingkungan dari segi bencana dan non bencana.

2. Menambah fitur informasi kelahiran dan kematian

3. Data yang ditambahkan oleh RT dan kelurahan langsung masuk ke database dan tampil pada halaman dashboard tidak melalui mitra.

\section{Daftar Pustaka}

[1] T. Baroš and T. Stojanović, "Geographic Information System (GIS) in Mapping of Mine Suspected Area in the Republic of Serpska,"
Glob. J. Sci. Front. Res. H Environ. Earth Sci., 2015.

[2] L. J. Awalin and B. M. Sukojo, "PEMBUATAN DAN ANALISA SISTEM INFORMASI GEOGRAFIS DISTRIBUSI JARINGAN LISTRIK (Studi Kasus: Surabaya Industrial Estate Rungkut di Surabaya)," MAKARA Technol. Ser., vol. 7, no. 1, pp. 33-44, 2010, doi: 10.7454/mst.v7i1.129.

[3] B. Li, S., S., D., \& Veenendaal, Advances in Web-based GIS, Mapping Services and Applications. London: CRC Press/Balkema.

[4] Open Street Map, "tentangopenstreetmap." http://openstreetmap.or.id/about/tenta ngopenstreetmap.

[5] Wesnawa, Geografi Permukiman. Yoyakarta: Graha Ilmu.

[6] Kartasapoetra, Potensi dan Sumber Daya. Jakarta: Erlangga, 1987.

[7] K. Kendall, Analisis dan Perancangan Sistem. Jakarta: PT.Indeks., 2010. 